\title{
Predlogi postopkov za določitev optimalnega števila in lokacij kontrol- nih pasti, kontrolnih nastav in lovnih nastav za osmerozobega smreko- vega lubadarja (Ips typographus)
}

\author{
Nikica OGRIS ${ }^{1 *}$, Marija KOLŠEK ${ }^{2}$, Maarten de GROOT $^{1}$
}

\begin{abstract}
Povzetek
V prispevku opisujemo predloge postopkov za izračun optimalnega števila in lokacij kontrolnih pasti za namen kontrole gostote populacije, kontrolnih nastav za preprečevalno zatiranje in lovnih nastav za zatiranje osmerozobega smrekovega lubadarja, Ips typographus (Linnaeus, 1758).
\end{abstract}

Ključne besede: kontrolna past, kontrolna nastava, lovna nastava, optimizacija, protokol, osmerozobi smrekov lubadar, Ips typographus, smreka, Picea abies, spremljanje, monitoring

\section{Uvod}

V Sloveniji imamo vzpostavljen sistem spremljanja gostote populacij dveh vrst smrekovih podlubnikov, in sicer osmerozobega smrekovega lubadarja (I. typographus) in šesterozobega smrekovega lubadarja (Pityogenes chalcographus (Linnaeus, 1761)) z uporabo kontrolnih pasti s feromonskimi vabami, ki jih namešča Zavod za gozdove Slovenije (ZGS) na podlagi letnega programa varstva gozdov, strokovnih navodil (Kolšek in Jakša, 2012b) in Pravilnika o varstvu gozdov (RS, 2009).

Kontrolne pasti in kontrolne nastave se prednostno namestijo $\mathrm{v}$ gozdovih, ki so starejši od 60 let in imajo lesno zalogo smreke več kot $50 \%$, ter kjer so se v preteklih letih pojavljale namnožitve smrekovih podlubnikov, in sicer se praviloma namesti ena past ali nastava na 50 ha (RS, 2009).

V letu 2020 je bilo za spremljanje gostote smrekovih podlubnikov v gozdovih uporabljenih 3.340 kontrolnih pasti (Ogris in Kolšek, 2020). Za primerjavo, Avstrija ima približno štirikrat večjo površino gozdov (ok. 4,0 milijonov ha) vendar ima za namen kontrole gostote populacije smrekovih podlubnikov samo 185 kontrolnih pasti (Krehan in Steyrer, 2016). Zato domnevamo, da število kontrolnih pasti za namen kontrole gostote populacije podlubnikov v Sloveniji ni optimalno. Poleg tega domnevamo, da tudi njihova razporejenost ni optimalna glede na lokalne razlike $\mathrm{v}$ klimatskih in ekoloških značilnostih območij, ki pomembno vplivajo na populacijsko dinamiko smrekovih podlubnikov.

Postavitev in vzdrževanje pasti (menjava feromonskih vab, čiščenje, pasti) namreč poleg delovne sile zahtevata tudi relativno velik materialni finančni vložek, razlike v klimatskih in ekoloških značilnostih lokacij posameznih pasti pa vplivajo na razliko $v$ fenologiji hroščev. Z inovativno zasnovo omrežja feromonskih pasti, ki bi temeljilo na upoštevanju vrednosti ključnih dejavnikov razvoja smrekovih podlubnikov na posameznih lokacijah po Sloveniji, bi sedanje stroške lahko zmanj- šali, hkrati pa bi povečali zanesljivost napovedi prenamnožitev populacij, kar bi omogočalo učinkovitejše in bolj ekonomično načrtovanje in izvajanje (preprečevalno-zatiralnih) ukrepov proti prenamnožitvam smrekovih podlubnikov.

Cilj raziskave je bil razviti predlog postopkov za določitev optimalnega števila in lokacij kontrolnih pasti za namen kontrole gostote populacije, kontrolnih nastav za preprečevalno zatiranje in lovnih nastav za zatiranje $I$. typographus. Predlagani postopki temeljijo na neobjavljenih rezultatih raziskave (Ogris, 2020). Zato v uvodnem delu vsakega od postopkov podajamo znanstvene osnove, ki so usmerjale razvoj teh postopkov.

Integralna metoda obvladovanja podlubnikov temelji na treh sklopih ukrepov (Titovšek, 1988): (a) preprečevalni (preventivni) ukrepi, (b) preprečevalno-zatiralni (profilaktični) ukrepi, (c) zatiralni (kurativni, represivni) ukrepi. Tako kontrolno-lovne pasti in kontrolno-lovne nastave uporabljamo $\mathrm{v}$ preprečevalno-zatiralnih ukrepih, ko je gostota populacije endemična, tj. pod pragom, ki označuje prenamnožitev. Ko pride do prenamnožitve podlubnikov, pričnemo z izvajanjem zatiralnih ukrepov, ki med drugimi vključujejo tudi uporabo lovnih pasti in lovnih nastav. Namen naše raziskave ni bil celostna obravnava integralnega varstva pred podlubniki, kakor je to zajel Titovšek (1988) v svoji monografiji. V naši raziskavi kontrolno-lovne pasti imenujemo kontrolne, ker smo želeli poudariti, da je predlog postopka namenjen zgolj kontroli gostote populacije smrekovih podlubnikov, manj pa zmanjševanju gostote njihovih populacij (preprečevanju namnožitve) oz. uničevanju ujetih hroščev.

\section{Predlog postopka za določitev optimalnega šte- vila in lokacij kontrolnih pasti \\ 2.1 Uvodna dejstva}

Namen kontrolne pasti je spremljanje gostote populacije I. typographus, tj. ugotavljanje ali je populacija prenamnožena, ali se bo zgodil izbruh in napad zdravih gostiteljev v tekočem letu na vplivnem območju pasti.

Spomladanski ulov v tem prispevku razumemo kot kumulativni ulov v kontrolni pasti od datuma prvega rojenja do datuma zaključka razvoja prve generacije, kot ju napove model RITY (Ogris in sod., 2019).

Spomladanski ulov v pasteh pozitivno korelira s količino evidentiranih lubadark v bližini v prejšnjem letu. Najmanjša še statistično značilna korelacija je bila v kolobarju s polmerom $4 \mathrm{~km}$ in širino $500 \mathrm{~m}$ (premer $8 \mathrm{~km}$ ) (Ogris, 2020). Sklep: kontrolne pasti ni treba postavljati $\mathrm{v}$ bližino lanskih žarišč, ker podatek o prenamnoženosti populacije dobimo že iz sanitarne sečnje smreke zaradi I. typographus. 
Spomladanski ulov v pasteh pozitivno korelira tudi s količino evidentiranih lubadark v bližini v tekočem letu. Najvišja korelacija je bila zabeležena v kolobarju s polmerom $4 \mathrm{~km}$ in širino $500 \mathrm{~m}$ (premer $8 \mathrm{~km}$ ) (Ogris, 2020).

Kontrolne pasti je treba postaviti pravočasno. Če pasti niso postavljene pravočasno, se korelacija ulova $\mathrm{V}$ pasti in količine evidentiranih lubadark v tekočem letu bistveno zmanjša (do 400\%) (Ogris, 2020).

Populacija I. typographus je na lokaciji pasti prenamnožena, če spomladanski ulov v eni pasti šteje 7.000 ali več osebkov I. typographus (Ogris, 2020). Na takšnih lokacijah navadno pride do napada zdravih smrek in posledično sanitarne sečnje smreke zaradi podlubnikov.

\subsection{Predlog postopka}

Predlog postopka za izračun optimalnega števila in lokacij kontrolnih pasti za I. typographus za namen ugotavljanja prenamnožitve populacij na vplivnem območju pasti je naslednji:

1. Izdelava karte iz evidence ZGS izbire smreke za sanitarni posek zaradi podlubnikov v lanskem letu. Vzamemo centroide odsekov, kjer je bil zabeležen sanitarni posek zaradi podlubnikov v lanskem letu in zarišemo kroge s polmerom $4000 \mathrm{~m}$, s čimer pridobimo karto 1, ki predstavlja območja, kjer pasti ni treba postavljati.

2. Izdelava karte gozdov, kjer se pojavlja smreka $\mathrm{z}$ lesno zalogo večjo kot nič (karta 2). Karto pridobimo $\mathrm{z}$ generalizacijo sestojne karte.

3. Izdelati razliko med karto 1 in $2, \mathrm{~s}$ čimer pridobimo območja, kjer se pojavlja smreka in v lanskem letu ni bilo zabeleženih žarišč (karta 3 ). Na teh lokacijah je potrebna kontrola gostote populacije I. typographus s kontrolnimi pastmi.

4. Identificirati modelne celice $8 \times 8 \mathrm{~km} \mathrm{~s}$ prisotnostjo smreke, kjer v lanskem letu ni bilo žarišč:

a. Izdelati presek mreže $8 \times 8 \mathrm{~km} \mathrm{~s}$ karto 2 (karta 4a)

b. Izdelati presek mreže $8 \times 8 \mathrm{~km} \mathrm{~s}$ karto 3 (karta 4b)

c. Identificirati modelne celice, kjer ni bilo zaznanih žarišč v prejšnjem letu: površina $(4 \mathrm{a})=$ površina (4b), s čimer pridobimo karto $4 \mathrm{c}$

5. Dodatna pravila:

a. Vsaj $10 \%$ površine modelske celice morajo zasedati sestoji s smreko, sicer kontrolne pasti ne postavimo.

b. Dodatno pravilo za obravnavo robnih celic na državni meji: če je imela vsaj ena sosednja modelska celica žarišče v lanskem letu, se domneva, da jo je imela tudi robna celica na državni meji.

6. $\mathrm{V}$ identificiranih modelskih celicah se postavi po ena kontrolna feromonska past in vloži se feromonska vaba za I. typographus.

a. Če modelska celica seka različne krajevne enote ZGS (KE), se past postavi v tisto KE, ki ima najmanj smreke, izraženo $\mathrm{v}$ deležu lesne zaloge, ker je količina ulova $\mathrm{v}$ pasti v negativni korelaciji s količino smreke v lesni zalogi v bližini pasti (Ogris, 2020).
7. Past moramo postaviti pred pričetkom rojenja $I$. typographus, kot ga napove model RITY. Če rojenje zamudimo, pasti ne postavimo.

8. Past redno spremljamo enkrat na teden in merimo ulov v pasti. Podatke o ulovu sproti vnašamo v računalniški program Varstvo gozdov (Ogris, 2012a, 2012b).

9. Past spremljamo do konca razvoja prve generacije, kot ga napove model RITY. Past se potem pospravi.

10. Populacija I. typographus je na lokaciji pasti (modelski celici) prenamnožena, če se je v obdobju od pričetka spomladanskega rojenja do konca razvoja prve generacije $\mathrm{v}$ eno past ulovilo 7.000 ali več osebkov I. typographus (Ogris, 2020).

Splošno pravilo:

- Minimalno število kontrolnih pasti je ena past na KE, kjer je delež lesne zaloge smreke vsaj 5 $\%$ (64 KE). V teh pasteh trajno spremljamo $I$. typographus vsako leto (kontrola enkrat na teden) in sicer od začetka marca do konca oktobra, lokacije teh pasti načeloma ne spreminjamo, zato takšne pasti imenujemo stalne pasti.

\section{Predlog postopkov za določitev optimalnega šte- vila in lokacij kontrolnih in lovnih nastav (dreves in} debel)

\subsection{Uvodna dejstva}

Predlog postopkov za določitev optimalnega števila in lokacij nastav uporabljamo kot priporočila.

Namen nastav je zmanjšati gostoto populacije $I$. typographus na lokacijah, kjer:

1. bo v tekočem letu prišlo do prenamnožitve populacije I. typographus, kar ugotovimo s kontrolnimi pastmi (če je ugotovljena namnožitev, govorimo o lovni nastavi),

2. je gostota populacije I. typographus nizka, tj. še pod pragom, ki kaže na prenamnožitev ( $\mathrm{v}$ tem primeru je to kontrolna nastava).

Lovne nastave (lovna debla, lovna drevesa) so lahko do 31-krat bolj učinkovite kot režaste pasti opremljene s feromonsko vabo za I. typographus (Raty in sod., 1995). V pasti se ujame le manjši delež celotne populacije podlubnikov (Fettig in Hilszczanski, 2015). Raziskava iz severovzhodne Italije je ugotovila, da uporaba lovnih pasti in lovnih nastav zmanjša napadenost dreves, vendar pa ni pokazala statističnih razlik $\mathrm{v}$ učinkovitosti med obema metodama (Faccoli in Stergulc, 2008).

Za kontrolo gostote populacije I. typographus so ekonomsko bolj učinkovite kontrolne pasti (režaste pasti s feromonsko vabo) (Bakke, 1989). Zato za kontrolo uporabljamo pasti, za lov pa nastave.

Nastave niso učinkovite na območjih aktivnih žarišč z lubadarkami. Zato nastav na takšnih območjih ni smiselno polagati (Jurc in sod., 2017).

Nastave so učinkovite samo na območjih, kjer je prišlo do prenamnožitve populacije I. typographus v tekočem letu, kar smo ugotovili s kontrolnimi pastmi (lahko tudi s kontrolno-lovnimi nastavami, vendar tega $\mathrm{v}$ naši raziskavi nismo obravnavali). 
Nastave so najbolj učinkovite pri ulovu smrekovih podlubnikov v polmeru do $1 \mathrm{~km}$ (Ogris, 2020).

Nastave položimo najkasneje tik pred rojenjem (Holuša in sod., 2017).

Debelejše smreke ulovijo večjo količino podlubnikov (Holuša in sod., 2017). V gozdnem sestoju za nastave uporabimo vitalne, sveže, $\mathrm{z}$ vodo ustrezno preskrbljene (ne izsušene) smreke debelejših dimenzij, ki so lahko (v lesno pridelovalnem smislu) slabše kakovosti.

Prenamnoženost populacije I. typographus ugotavljamo s kontrolnimi feromonskimi pastmi (glej protokol za kontrolne pasti).

Populacija I. typographus je prenamnožena, če se je v obdobju od pričetka spomladanskega rojenja do konca razvoja prve generacije v eno past ulovilo 7.000 ali več osebkov I. typographus (Ogris, 2020).

3.2 Predlog postopka za položitev kontrolnih nastav za prezimele podlubnike (nastave I. serije)

1. Kontrolne nastave I. serije priporočamo položiti na območjih, kjer so kontrolne pasti v lanskem letu pokazale trend povečanja gostote populacije I. typographus.

2. Kontrolne nastave I. serije lahko položimo tudi na območjih, kjer je gostota populacije I. typographus visoka vendar pod pragom za gradacijo, tj. v lanskem spomladanskem ulovu je bilo v kontrolno past ujetih od 2.000 do 7.000 osebkov I. typographus.

3. Nastave položimo en teden pred pričakovanim rojenjem spomladi (Holuša in sod., 2017), pri čemer upoštevamo napoved modela RITY (Ogris in sod., 2019).

3.3 Predlog postopka za položitev lovnih nastav za prvo in drugo generacijo podlubnikov (nastave II. serije)

1. Nastav ne polagamo v modelskih celicah, kjer so bila ugotovljena žarišča podlubnikov v prejšnjem letu.

2. V modelskih celicah, kjer v lanskem letu vključno do marca $v$ tekočem letu ni prišlo do izbire smrek za posek zaradi podlubnikov, postavimo feromonske pasti (glej protokol za kontrolne pasti). S feromonskimi pastmi ugotovimo lokacije (modelske celice $8 \times 8 \mathrm{~km}$ ), kjer bo v tekočem letu prišlo do prenamnožitve I. typographus.

3. Nastave II. serije položimo na območjih (v modelskih celicah), kjer smo s kontrolnimi pastmi ugotovili, da je prišlo do prenamnožitve populacije $I$. typographus v tekočem letu (glej protokol za kontrolne pasti).

4. Nastave položimo čimbolj enakomerno po celotni modelski celici v medsebojni razdalji ok. $2 \mathrm{~km}$ (vsaj 16 lovnih nastav) (Ogris, 2020). Nastave položimo en teden pred pričakovanim rojenjem prve in druge generacije, pri čemer upoštevamo napoved rojenja modela RITY in lokalne razmere (Ogris in sod., 2019). Na eni lokaciji lahko položimo več lovnih nastav (do 10 nastav na hektar).

5. Nastave redno spremljamo (vsaj enkrat na teden). Ko je nastava polno zasedena (več kot ena vhodna odprtina na $\mathrm{dm}^{2}$ ) oz. najpozneje, ko se na delu na- stave, ki je bil prvi napaden, nova generacija podlubnikov razvije do razvojne faze bube ali mladega hrošča, moramo nastave izdelati (olupimo), skorjo in zalego uničimo (zažgemo) (glej strokovna navodila za nastave) (Kolšek in Jakša, 2012a). Dodatni napotki:

a. Beljenje lahko opravimo v gozdu, ali pa sortimente prepeljemo v skladišča z lupilnimi linijami.

b. Če so nastave na eni lokaciji polno zasedene (več kot ena vhodna odprtina na $\mathrm{dm}^{2}$ povprečno na več kot $50 \%$ površine nastave), priporočamo zraven položiti še najmanj eno dodatno lovno nastavo.

\section{Zaključek}

$\mathrm{Na}$ znanstvenih osnovah smo razvili predlog postopkov za optimizacijo števila kontrolnih pasti, kontrolnih nastav in lovnih nastav za I. typographus. Optimizirali smo tudi razporeditev kontrolnih pasti, kontrolnih nastav in lovnih nastav, ker postopki upoštevajo lokalne razlike v klimatskih in ekoloških značilnosti območij ter fenologijo smrekovih podlubnikov. Predlogi postopkov so bili usklajeni z Zavodom za gozdove Slovenije in predstavljeni na delavnici, kjer so udeleženci potrdili, da sta postopka izvedljiva v praksi.

Optimalno število in lokacij kontrolnih pasti, kontrolnih nastav in lovnih nastav bo vsako leto določil Gozdarski inštitut Slovenije v okviru Poročevalsko, prognostično-diagnostične službe za gozdove (Javna gozdarska služba). Razvili bomo javno dostopni spletni aplikaciji za načrtovanje števila in lokacij kontrolnih pasti ter kontrolnih in lovnih nastav po posameznih ureditvenih enotah Zavoda za gozdove Slovenije. Spletni aplikaciji bosta del nadgradnje obstoječega elektronskega sistema za varstvo gozdov Slovenije in njegov integralni del (www.zdravgozd.si), neposredni uporabniki sistema pa bodo zaposleni $\mathrm{v}$ Javni gozdarski službi (ZGS in GIS).

Do sedaj je Zavod za gozdove Slovenije spremljal ok. 3.300 kontrolno-lovnih pasti letno (Ogris in Kolšek, 2020). Nov predlog predvideva maksimalno 366 kontrolnih pasti (eno past na modelsko celico dimenzij $8 \times$ $8 \mathrm{~km}$ ) in minimalno 64 pasti, ki bi se spremljale trajno. Tako nov predlog predvideva od 9- do 52-krat manj kontrolnih pasti kot do sedaj. Poudariti je treba, da kontrolne pasti lahko uporabljamo tudi v okviru drugih preprečevalno-zatiralnih ukrepov, redkeje pa tudi zatiralnih ukrepov. V drugem primeru jih imenujemo lovne pasti. Vendar to presega cilj naše raziskave in jih tukaj nismo obravnavali.

Za primerjavo, Titovšek (1988) je predlagal medsebojno oddaljenost $250-500 \mathrm{~m}$ med posameznimi kontrolno-lovnimi nastavami ali pastmi, kar ustreza gostoti ena past na 6,25-25,0 ha, kar je še najmanj dvakrat gosteje kakor določa Pravilnik o varstvu gozdov, tj. ena past ali nastava na 50 ha (RS, 2009). Tukaj je nujno poudariti različen namen pasti, tj. Titovšek (1988) govori o celotni vlogi kontrolno-lovnih pasti, mi pa smo se v našem prispevku omejili le na njihovo vlogo pri spremljanju (monitoringu) populacij vrste I. typographus.

Drastično zmanjšanje pasti v smislu spremljanje gostote podlubnikov bi pomenilo velik prihranek za 
ZGS in državo pri materialnih stroških za postavitev in čiščenja pasti (pasti, feromonske vabe, stojala za postavitev pasti, prevozni stroški) in tudi prihranek pri delu (delovnih urah). Sproščeni viri (sredstva) se bi tako lahko uporabili za druge pomembnejše aktivnosti, kot je npr. za iskanje lubadark in za iskanje invazivnih tujerodnih vrst.

Poleg zmanjšanja stroškov bi postopki hkrati povečali zanesljivost napovedi prenamnožitev smrekovih podlubnikov zaradi kakovostnejših podatkov, kar bi omogočalo učinkovitejše in bolj ekonomično načrtovanje in izvajanje profilaktičnih (preprečevalno-zatiralnih) ukrepov proti prenamnožitvam smrekovih podlubnikov.

Predlagali smo tudi optimizacijo postopka za določitev števila in lokacij kontrolnih nastav in lovnih nastav. Postopek je podoben dosedanjim strokovnim navodilom za polaganje in spremljanje kontrolnih in lovnih nastav (Kolšek in Jakša, 2012a). Predlog predvideva večjo spremembo v smislu, da bolj podrobno določa načelne lokacije za polaganje in samo število nastav.

Vendar da se bodo predlogi postopkov lahko pričeli dejansko uporabljati v praksi, bo treba posodobiti Pravilnik o varstvu gozdov (RS, 2009).

V naši raziskavi smo predlagali postopke za določitev optimalnega števila in lokacij kontrolnih pasti za namen kontrole gostote populacije I. typographus in kontrolnih (za preprečevanje namnožitve) ter lovnih nastav (za zatiranje) I. typographus. Obravnavali smo le omejen izbor ukrepov integralnega obvladovanja podlubnikov iz sklopa preprečevalno-zatiralnih in zatiralnih ukrepov. Kljub temu ne smemo pozabiti, da je poglavitni preprečevalno-zatiralni in zatiralni ukrep zoper smrekove podlubnike sanitarna sečnja, izdelava lubadark in uničenje podlubnikov pred izletom podlubnikov iz lubadark in ostalega napadenega materiala (RS, 2009; Titovšek, 1988).

\section{Zahvala}

Raziskava je nastala v okviru ciljnega raziskovalnega projekta "Izboljšanje sistema spremljanja ulova smrekovih podlubnikov $\mathrm{v}$ kontrolne feromonske pasti in sistema polaganja kontrolnih nastav ter izdelava aplikacije za načrtovanje lokacij in števila kontrolnih pasti ter kontrolnih nastav po ureditvenih enotah Zavoda za gozdove Slovenije (V4-1822)", ki ga financirata Ministrstvo za kmetijstvo, gozdarstvo in prehrano ter Javna agencija za raziskovalno dejavnost Republike Slovenije. Trem recenzentom se zahvaljujemo za kritičen pregled in koristne pripombe, na podlagi katerih smo lahko izboljšali kakovost članka.

\section{Viri}

Bakke A. 1989. The recent Ips typographus outbreak in Norway: experiences from a control program. Holarctic Ecology, 12, 4: 515519. http://www.jstor.org/stable/3682063

Faccoli M., Stergulc F. 2008. Damage reduction and performance of mass trapping devices for forest protection against the spruce bark beetle, Ips typographus (Coleoptera Curculionidae Scolytinae). Annals of Forest Science, 65, 3: 309-309. https://doi.org/10.1051/forest:2008010. 10.1051/forest:2008010

Fettig C.J., Hilszczanski J. 2015. Management strategies for bark beetles in conifer forests. V: Bark Beetles. Biology and Ecology of Native and Invasive Species. Vega F.E., Hofstetter R.W. (eds.). Amsterdam, Boston, Heidelberg, London, New York, Oxford, Paris, San Diego, San Francisco, Singapore, Sidney, Tokio, Academic Press: 555-584

Holuša J., Hlásny T., Modlinger R., Lukášová K., Kula E. 2017. Felled trap trees as the traditional method for bark beetle control: Can the trapping performance be increased? Forest Ecology and Management, 404: 165-173. https://doi.org/10.1016/j.foreco.2017.08.019

Jurc M., Pavlin R., Kavčič A., de Groot M., Hauptman T. 2017. Priporočila za uporabo različnih biotehniških metod in kemičnih sredstev za obvladovanje podlubnikov (Curculionidae: Scolytinae). Gozdarski vestnik, 75, 2: 94-111

Kolšek M., Jakša J. 2012a. Navodila za postavitev in izdelavo kontrolnih in lovnih nastav za podlubnike. V: Navodila za preprečevanje in zatiranje škodljivcev in bolezni gozdnega drevja v Sloveniji: Priročnik za javno gozdarsko službo. Jurc D., Kolšek M. (eds.). Ljubljana, Gozdarski inštitut Slovenije, Silva Slovenica: 28-31

Kolšek M., Jakša J. 2012b. Navodila za postavitev in vzdrževanje kontrolnih in kontrolno-lovnih pasti za smrekove podlubnike. V: Navodila za preprečevanje in zatiranje škodljivcev in bolezni gozdnega drevja v Sloveniji. Jurc D., Kolšek M. (eds.). Ljubljana, Gozdarski inštitut Slovenije, Silva Slovenica: 20-27

Krehan H., Steyrer G. 2016. Bark-beetle monitoring in Austria. waldwissen.net.

https://www.waldwissen.net/waldwirtschaft/schaden/insekten/bfw borkenkaefer-monitoring/index EN (15. 9. 2020)

Ogris N. 2012a. Priročnik za računalniški program Varstvo gozdov. Ljubljana, Gozdarski inštitut Slovenije: 36 str.

Ogris N. 2012b. Prognostične osnove za varstvo gozdov Slovenije. Ljubljana, Silva Slovenica: 104 str.

Ogris N. 2020. Znanstvene osnove za optimizacijo števila in lokacij kontrolnih pasti in lovnih nastav. Ljubljana, Gozdarski inštitut Slovenije (neobjavljeno)

Ogris N., Ferlan M., Hauptman T., Pavlin R., Kavčič A., Jurc M., De Groot M. 2019. RITY - A phenology model of Ips typographus as a tool for optimization of its monitoring. Ecological Modelling, 410: 108775. https://doi.org/10.1016/j.ecolmodel.2019.108775

Ogris N., Kolšek M. 2020. Namnožitev osmerozobega in šesterozobega smrekovega lubadarja v Sloveniji v 2020. Napovedi o zdravju gozdov, 2020. http://dx.doi.org/10.20315/NZG.54

Raty L., Drumont A., De Windt N., Grégoire J.-C. 1995. Mass trapping of the spruce bark beetle Ips typographus L.: traps or trap trees? Forest Ecology and Management, 78, 1: 191-205. https://doi.org/10.1016/0378-1127(95)03582-1

RS. 2009. Pravilnik o varstvu gozdov. Uradni list RS, 114-5220/2009 in $31 / 2016$

Titovšek J. 1988. Podlubniki (Scolytidae) Slovenije: obvladovanje podlubnikov. Ljubljana, Zveza društev inženirjev in tehnikov gozdarstva in lesarstva Slovenije, Gozdarska založba: 128 str.
1 Gozdarski inštitut Slovenije, Večna pot 2, 1000 Ljubljana; ${ }^{2}$ Zavod za goz-
dove Slovenije, Večna pot 2, 1000 Ljubljana *nikica.ogris@gozdis.si 